\title{
Differential expression of TgMIC1 in isolates of Chinese 1 Toxoplasma with different virulence
}

\author{
Yang Wang ${ }^{1 \dagger}$, Chengjian Han ${ }^{1,2 \dagger}$, Rongsheng zhou ${ }^{2 \dagger}$, Jinjin Zhu ${ }^{1}$, Famin Zhang ${ }^{1}$, Jingyang Li ${ }^{1,2}$, Qingli Luo ${ }^{1}$, \\ Jian Du ${ }^{1,3}$, Deyong Chu ${ }^{1}$, Yihong Cai ${ }^{1,4}$, Jilong Shen ${ }^{1}$ and Li Yu ${ }^{1 *}$
}

\begin{abstract}
Background: The predominant genotype of Toxoplasma in China is the Chinese 1 (ToxoDB\#9) lineage. TgCtwh3 and TgCtwh6 are two representative strains of Chinese 1, exhibiting high and low virulence to mice, respectively. Little is known regarding the virulence mechanism of this non-classical genotype. Our previous RNA sequencing data revealed differential mRNA levels of TgMIC1 in TgCtwh3 and TgCtwh6. We aim to further confirm the differential expression of TgMIC1 and its significance in this atypical genotype.
\end{abstract}

Methods: Quantitative real-time PCR was used to verify the RNA sequencing data; then, polyclonal antibodies against TgMIC1 were prepared and identified. Moreover, the invasion and proliferation of the parasite in HFF cells were observed after treatment with TgMIC1 polyclonal antibody or not.

Results: The data showed that the protein level of TgMIC1 was significantly higher in high-virulence strain TgCtwh3 than in low-virulence strain TgCtwh6 and that the invasion and proliferation of TgCtwh3 were inhibited by TgMIC1 polyclonal antibody.

Conclusion: Differential expression of TgMIC1 in TgCtwh3 and TgCtwh6 may explain, at least partly, the virulence mechanism of this atypical genotype.

Keyword: Toxoplasma gondii, Invasion, Microneme protein 1, Polyclonal antibody

\section{Background}

Toxoplasma gondii is an intracellular parasite belonging to the phylum Apicomplexa that infects a wide range of warm-blooded vertebrates, including approximately one-third of humans [1]. In most hosts, this intracellular protozoan parasite escapes immunological surveillance and can cross the blood-brain and blood-retina barrier reaching alleged immune privileged regions to establish a

\footnotetext{
${ }^{*}$ Correspondence: lilyyu33@126.com

${ }^{\dagger}$ Yang Wang, Chengjian Han, and Rongsheng Zhou contributed equally to this work

${ }^{1}$ Department of Microbiology and Parasitology, Anhui Provincial Laboratory of Microbiology and Parasitology; Anhui Key Laboratory of Zoonoses, School of Basic Medical Sciences, Anhui Medical University, 81 Meishan Road, Hefei 230032, Anhui Province, People's Republic of China

Full list of author information is available at the end of the article
}

life-long latent infection [2]. The opportunistic characteristic of T. gondii has rendered most infected healthy individuals asymptomatic. However, in immunosuppressed or congenitally infected individuals, infection can cause encephalitis, ocular disease or even death and is of great clinical importance [3]. Therefore, a better understanding of the molecular mechanisms responsible for the differences in the virulence of $T$. gondii is needed to develop effective vaccines or drugs to control the spread of toxoplasmosis.

It is perhaps unsurprising that T. gondii subverts host protein networks depending on the infected cell type and the parasite genotype. Genomic differences in $T$. gondii strains (types I, II and III are the classical North American and European strains) are typically revealed by techniques such as restriction fragment length polymorphisms or isoenzyme markers [4]. Type I strains have a

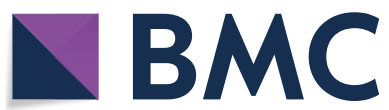

(c) The Author(s) 2021. This article is licensed under a Creative Commons Attribution 4.0 International License, which permits use, sharing, adaptation, distribution and reproduction in any medium or format, as long as you give appropriate credit to the original author(s) and the source, provide a link to the Creative Commons licence, and indicate if changes were made. The images or other third party material in this article are included in the article's Creative Commons licence, unless indicated otherwise in a credit line to the material. If material is not included in the article's Creative Commons licence and your intended use is not permitted by statutory regulation or exceeds the permitted use, you will need to obtain permission directly from the copyright holder. To view a copy of this licence, visit http://creativecommons.org/licenses/by/4.0/. The Creative Commons Public Domain Dedication waiver (http://creativecommons.org/publicdomain/zero/1.0/) applies to the data made available in this article, unless otherwise stated in a credit line to the data. 
high level of acute virulence in laboratory mice, with an $\mathrm{LD}_{100}$ as low as a single tachyzoite. Although the type II strain has relatively reduced virulence, it is most commonly associated with human infections. Type III strain is avirulent and always exists in domestic and wild animals; it is rarely found in human infections [5]. Compared to the North American and European strains, South American strains show more complex and diverse genetic polymorphisms. More importantly, the predominant genotype of $T$. gondii in China is Chinese I (ToxoDB\#9) lineage (> 79\% based on 60 isolates) [6]. Furthermore, our previous studies have demonstrated that the isolates of Chinese I vary in their virulence in mice; among these, $\mathrm{TgCtwh} 3$ exhibits high virulence, whereas TgCtwh6 exhibits low virulence [6-8].

Upon infection, $T$. gondii tachyzoites are surrounded by a non-fusogenic compartment, termed the parasitophorous vacuole (PV), to survive in the host cytoplasm by avoiding lysosomal degradation $[9,10]$. This active process depends on the discharge of parasite proteins from its specialized set of secretory organelles, namely micronemes, rhoptries and dense granules. Among these, proteins secreted from the micronemes (MICs) are involved in the initial recognition, attachment and invasion, whereas those secreted from the dense granules (GRAs) and rhoptries (ROPs) participate in modulating a variety of host signals to establish a suitable environment for parasite growth [11, 12]. Revealed by genetic manipulation, some TgMIC proteins are proved to be critical virulence factors including TgMIC1. Rather than relying on transmembrane (TM) domains or glycosylphosphatidylinositol (GPI) anchors, TgMIC1 contains two microneme adhesive repeat (MAR) domains that form a complex with TgMIC4/TgMIC6 to achieve surface localization [13, 14]. The critical role of TgMIC1 in parasite invasion and contributing to virulence in mice has been reported $[15,16]$. Additionally, a recent study showed that TgMIC1 directly binds to the N-glycans of TLR2, thereby affecting systemic levels of IL-12 and IFN- $\gamma$ in vivo [17]. In this study, we aim to describe the differential expression levels of the TgMIC1 gene in TgCtwh3 and TgCtwh6. Furthermore, given its influential role in T. gondii infection competency and murine pathogenesis, TgMIC1 could be a critical virulence factor between these two strains. To investigate this possibility, differences in TgMIC1 protein expression in TgCtwh3 and TgCtwh6 were evaluated using a polyclonal antibody.

\section{Methods}

\section{Cells and parasites}

Human foreskin fibroblast (HFF) cells were purchased from ATCC (SCRC-1041) and routinely maintained in Dulbecco's Modified Eagle Medium (DMEM, Gibco) supplemented with $10 \%$ fetal bovine serum (FBS, BI, Israel), $100 \mu \mathrm{g} / \mathrm{ml}$ penicillin and $100 \mu \mathrm{g} / \mathrm{ml}$ streptomycin (Sigma, USA) and maintained in an incubator at $37{ }^{\circ} \mathrm{C}$ and $5 \% \mathrm{CO}_{2}$. Toxoplasma gondii $\mathrm{RH}$ strain, green fluorescent protein-RH strain (GFP-RH), TgCtwh3 and TgCtwh6 were propagated in HFF cells.

\section{RNA extraction and quantitative real-time PCR assays}

Total RNA was extracted from the parasites using Trizol Reagent (Invitrogen, USA). Total RNA was used for reverse transcription with the cDNA synthesis kit (TaKaRa, Japan) according to the manufacture's protocol. cDNA synthesis was performed using SYBR-Green Master Mix (TaKaRa, Japan). The primer sequences used were as follows:

TgMIC1 forward, TCGGTTTATGCTGAGTGTGC; TgMIC1 reverse, GGCGAATTCCTTCCTCTTCT; TgMIC4 forward, GACATGACGGGATCCAGAAC; TgMIC4 reverse, CATGCAACTTGGCAGTCTGT; TgMIC6 forward, CATATCACCTGCAAGCGTGT; TgMIC6 reverse, GGCTCACGACTTTCACCTTC; $\beta$-tublin forward, GTCTCCACTTCTTCCTCATTG; $\beta$-tublin reverse, GTTCTTTGCGTCGAACATC.

$\beta$-Tublin was used as an internal control. Relative expression levels were calculated according to the standard $2^{-\Delta \Delta C}$ method. All experiments were performed in triplicate and repeated at least three times.

\section{Expression and purification of recombinant TgMIC1 proteins}

The coding sequence (CDS) of TgMIC1 was optimized by using the Optigene ${ }^{\mathrm{TM}}$ codon optimized analysis platform (Shanghai Jierui Bioengineering Co., Ltd.). The optimized TgMIC1 sequence was synthesized and cloned into pET30a. The recombinant pET30a-MIC1 plasmid was transformed into Escherichia coli BL21 (DE3), cultivated in Luria-Bertani (LB) at $37{ }^{\circ} \mathrm{C}$. The recombinant protein expression was induced by adding $0.5 \mathrm{mM}$ isopropyl $\beta$-D-1-thiogalactopyranoside (IPTG, Sigma, USA) at $16{ }^{\circ} \mathrm{C}$ overnight with constant shaking at $200 \mathrm{rpm}$. Then, the bacterial cells were harvested by centrifugation at $8000 \mathrm{rpm}$ for $6 \mathrm{~min}$ and resuspended in $20 \mathrm{ml} 10 \mathrm{mM}$ Tris-HCL buffer. The bacteria suspension was sonicated on ice (500 W, 180 times, $5 \mathrm{~s}$ each time, $5 \mathrm{~s}$ interval). The lysate was centrifuged at $12,000 \mathrm{rpm}$ for $10 \mathrm{~min}$ to separate the supernatant and bacterial debris. The level of $\mathrm{rTgMIC} 1$ expression was analyzed by $12 \%$ SDS-PAGE. Furthermore, the separated supernatants were collected and purified by Ni column (Ni Sepharose 6 Fast Flow, GE Healthcare). The purification efficiency was analyzed via $12 \%$ SDS-PAGE and the protein concentration measured by BCA Protein Quantitation Kit according to the instruction's protocol. 


\section{TgMIC1 polyclonal antibody preparation and specific identification}

For polyclonal antibody production, three 2-kg New Zealand white rabbits were immunized with $400 \mu \mathrm{g}$ of purified rTgMIC1 diluted in $200 \mu \mathrm{l}$ phosphate-buffered saline (PBS) and mixed with an equal volume of complete Freund's adjuvant (Sigma, USA), through multiple intradermal injections into the back of each rabbit. Two weeks later, the immunization was boosted with $200 \mu \mathrm{g} \mathrm{rTg-}$ MIC1 protein in Freund's incomplete adjuvant followed by a booster immunization once every 2 weeks. The ear vein blood was collected 7 days after the fourth immunization to measure the titer of antibodies by enzymelinked immunosorbent assay (ELISA). All rabbits were anesthetized by injecting $3 \%$ pentobarbital sodium $(1 \mathrm{ml} /$ $\mathrm{kg}$ ) at the base of the ear prior to the terminal cardiac puncture. The rabbit heart was then bled, and the antibodies were purified by Protein A [18]. The serum was mixed with an equal volume of the binding buffer to equilibrate the column. After the serum sample was loaded, the column was rinsed with binding buffer until the binding solution contained no protein. The presence of TgMIC1 polyclonal antibody was further identified by western blot and immunofluorescence assays.

\section{Protein isolation and western blot assays}

The $\mathrm{rTgMIC} 1$ and recombinant plasmid were prepared as described above. Parasites was lysed in the ice-cold RIPA lysis buffer (Beyotime, China) with 1\% phenyl methyl sulfonyl fluoride, and the total protein concentrations were detected by BCA Protein Quantitation Kit. The proteins $(20 \mu \mathrm{g})$ were subjected to electrophoresis in $8-10 \%$ polyacrylamide gel. The proteins were transferred onto a polyvinylidene fluoride membrane (Millipore, USA) by a standard western blot procedure. The membrane was blocked with $5 \%$ nonfat skim milk in TBS containing $0.1 \%$ Tween 20 for $1 \mathrm{~h}$ and incubated with specific primary antibodies against TgMIC1 (1:4000), Tg $\beta$-actin (1:2000) or HIS monoclonal antibodies $(1: 5000)$ at $4{ }^{\circ} \mathrm{C}$ overnight. Following incubation with the corresponding secondary antibodies (Santa Cruz Biotechnology, 1:10,000 diluted to $5 \%$ nonfat skim milk) conjugated to horseradish peroxidase for $1 \mathrm{~h}$, the membranes were visualized using ECL Western blotting substrate (Bio-RAD, USA). The band intensity was quantified using ImageJ software, and the TgMIC1 protein expression was normalized to the $\operatorname{Tg} \beta$ actin protein level.

\section{ELISA analysis}

The titer in the serum from immunized rabbits was performed with ELISA. The purified rMIC1 protein (200 ng/ $\mathrm{ml}$ ) was used to coat the plate at $4{ }^{\circ} \mathrm{C}$ overnight, followed by blocking with $5 \% \mathrm{BSA}$ at $37{ }^{\circ} \mathrm{C}$ for $60 \mathrm{~min}$. The serum sample was serially diluted from 1:200 to $1: 204,800$, and then $100 \mu \mathrm{l}$ of diluted sample was added to each well and incubated $60 \mathrm{~min}$ at $37{ }^{\circ} \mathrm{C}$. The samples were further incubated with secondary anti-rabbit antibodies (Zhongshan Golden Bridge, Beijing, China) diluted 1:5000 in PBS conjugated to horseradish peroxidase in each well for $1 \mathrm{~h}$. Then, the wells were incubated with $100 \mu \mathrm{l}$ tetramethylbenzidine (TMB, Beyotime, China) at $37{ }^{\circ} \mathrm{C}$ for $10 \mathrm{~min}$. Finally, $2 \mathrm{M} \mathrm{H}_{2} \mathrm{SO}_{4}(50 \mu \mathrm{l})$ was used to stop the reaction in the well, and the absorbance was read at $450 \mathrm{~nm}$. All results were repeated three to four times independently.

\section{Immunofluorescence staining}

HFF monolayers were grown on coverslips placed in wells of a 6-well plate at a density of $10^{5}$ cells per well and were incubated for $24 \mathrm{~h}$. Then, cells were challenged with T. gondii GFP-RH strains for $24 \mathrm{~h}$. After washing with PBS three times, the coverslips were fixed with $4 \%$ paraformaldehyde (PFA) for $20 \mathrm{~min}$. The coverslips were permeabilized with $0.1 \%$ Triton X-100 (Sigma, USA) for $30 \mathrm{~min}$, and blocked for $30 \mathrm{~min}$ at $37{ }^{\circ} \mathrm{C}$ with $5 \% \mathrm{BSA}$ in PBS. After washing again, the coverslips were then incubated with polyclonal antibody against TgMIC1 $(1: 1,000)$ overnight at $4{ }^{\circ} \mathrm{C}$, followed by goat anti-rabbit secondary antibodies conjugated to Alexa Fluor 594 (1:500, Invitrogen, USA). Images were recorded using a Zeiss LSM880 confocal microscope (Zeiss).

\section{Invasion assay}

HFF monolayers were grown on coverslips placed in wells of a 6-well plate at a density of $10^{5}$ cells per well and were incubated for $24 \mathrm{~h}$. First, cells were incubated with TgMIC1 polyclonal antibody at $37{ }^{\circ} \mathrm{C}$ for $16 \mathrm{~h}$. Then, the cells were challenged with $T$. gondii TgCtwh3 and TgCtwh6 strains for $1 \mathrm{~h}$. Non-adherent parasites were washed away with PBS before fixation with $4 \%$ PFA for $20 \mathrm{~min}$. Adherent external parasites were detected using rabbit anti- $T$. gondii glide-associated protein 45 (TgGAP45) antibodies (1:2000, gifted by Doctor Yonggen Jia, Department of Microbiology and Molecular Medicine, CMU, University of Geneva, Geneva 4, Switzerland) [19] followed by secondary anti-rabbit antibodies coupled to Alexa Fluor 488. After permeabilization with $0.1 \%$ Triton X-100 for $30 \mathrm{~min}$, intracellular and adherent external parasites were labeled with anti-GAP45 antibodies followed by secondary anti-rabbit antibodies coupled to Alexa Fluor 594. Data were compiled from three independent experiments. Ten fields were randomly selected in the same pattern (the operator moved the microscope stage without viewing the sample) for all samples, and the 
number of external and internal parasites was counted in a blinded manner.

\section{Intracellular growth assay}

HFF monolayers were incubated with TgMIC1 polyclonal antibody at $37{ }^{\circ} \mathrm{C}$ for $16 \mathrm{~h}$. The TgCtwh3 or TgCtwh 6 parasites were allowed to invade HFF cells for $24 \mathrm{~h}$. After washing with PBS three times, the coverslips were fixed with methyl alcohol for $5 \mathrm{~min}$ followed by the Wright Giemsa method and observed under a microscope. Fifty

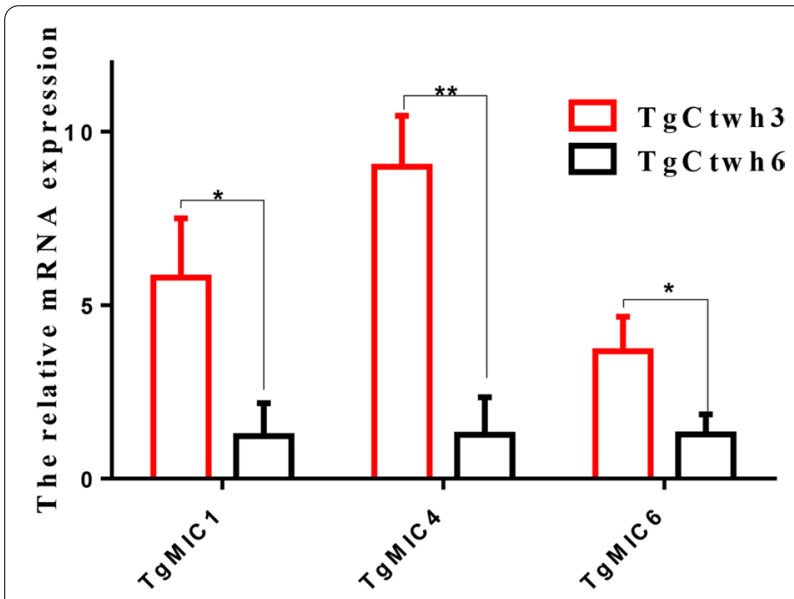

Fig. 1 Quantitative real-time PCR analysis of TgMIC1, TgMIC4 and TgMIC6 mRNA expression in TgCtwh3 and TgCtwh 6 strains. ${ }^{*} p<0.05$, ${ }^{*} p<0.01$ versus TgCtwh6 group. Data are represented as mean \pm SD for three independent experiments
PVs were randomly selected, and the number of T. gondii tachyzoites in each PV was counted.

\section{Statistical analysis}

Statistical results are shown with values expressed as means \pm standard deviation of at least three independent experiments. The statistical significance of differences was performed using one-way ANOVA and $t$-test. Values of $p<0.05$ were considered statistically significant.

\section{Results}

Differential mRNA expression of TgMIC1/4/6 in TgCtwh3 and TgCtwh6 strains

Virulence genes were identified by comparing and studying the differential gene expression between the TgCtwh3 and TgCtwh6 strains. Quantitative real-time PCR was used to identify the mRNA expression of TgMIC1, TgMIC4 and TgMIC6 in TgCtwh3 and TgCtwh6 strains. Significantly high expressions of TgMIC1 ( $t$-test: $t$ $(4)=4.047, p=0.015)$, TgMIC4 (t-test: $t(4)=7.331$, $p=0.0018)$ and TgMIC6 ( $t$-test: $t(4)=3.609, p=0.022)$ were observed in the virulent TgCtwh3 compared with the less virulent TgCtwh6 (Fig. 1).

\section{Codon optimization and efficiency of the TgMIC1 gene}

Optigene $^{\mathrm{TM}}$ Codon Optimization Analysis Platform was used to optimize multiple important parameters of the TgMIC1 gene to stabilize DNA fragments and in turn increase gene expression efficiency. After optimization, the TgMIC1 Codon Adaption Index (CAI) increased

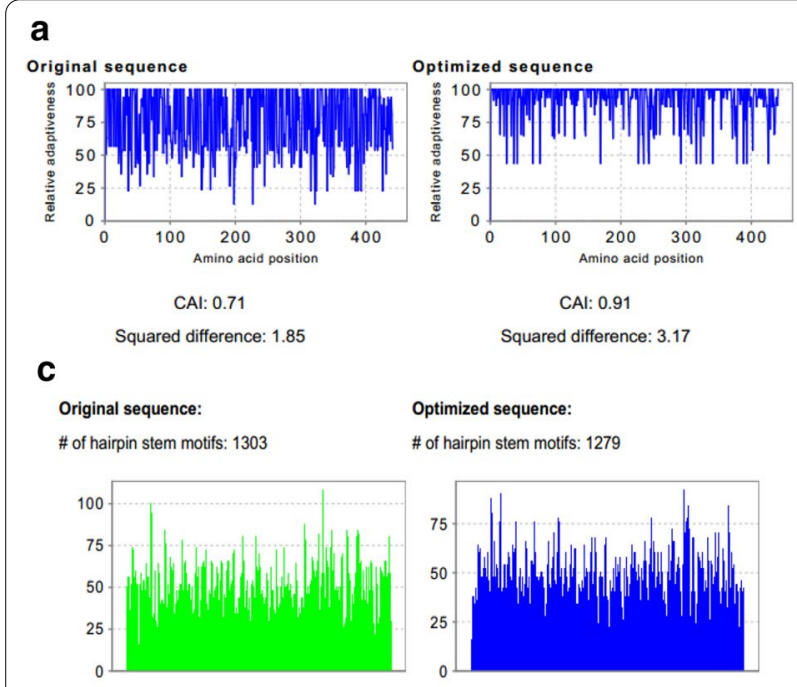

b

Original sequence:

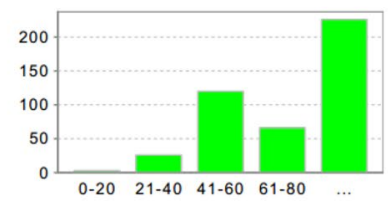

Optimized sequence:

\section{d}

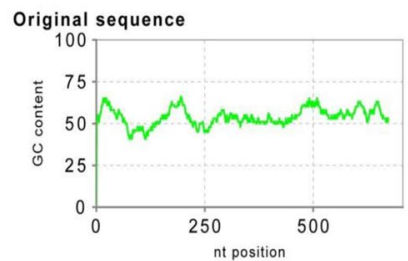

Total GC: $53.00 \%$
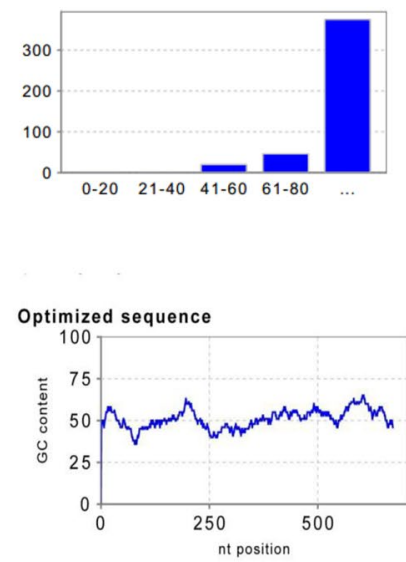

Total GC: $49.00 \%$

Fig. 2 Optimization of TgMIC1 codon sequences. a Relative adaptiveness distribution of the original and optimized gene sequences. CAI $>0.9$ is regarded as very good in terms of a high gene expression level. $\mathbf{b}$ The percentage distribution of codons in the original and optimized groups. A value of 100 is set for the codon with the highest usage frequency for a given amino acid in the desired expression organism. c Total GC content of the original and optimized genes. $\mathbf{d}$ Comparison of the mRNA secondary structure between the original and optimized groups 
from 0.74 to 0.91 , reaching a high gene expression level (Fig. 2a). The frequency of optimal codons (FOP) for TgMIC1 was maintained above 80 , which was significantly higher than that of the original sequence (Fig. $2 b$ ). The number of secondary structures of mRNA in the TgMIC1 optimized group was slightly lower (Fig. 2c). Moreover, the GC\% peaks were removed in a 60-bp window, and the ideal percentage range of GC content was between 30 and $70 \%$. The GC content of the optimized group was lower than that of the previous group (Fig. 2d). The results revealed that the optimized sequence of TgMIC1 was more suitable for the next experiment than the original sequence.

\section{Expression, purification and identification of the recombinant TgMIC1 protein}

The recombinant plasmid pET-30a-MIC1 was successfully constructed. rTgMIC1 was expressed in Escherichia coli strain BL21 (Fig. 3a-b) and identified by HIS monoclonal antibodies (Fig. 3c). Western blot and SDS-PAGE analysis indicated that $\mathrm{rTgMIC} 1$ had a molecular weight of approximately $60 \mathrm{kDa}$, which was consistent with the predicted combined sizes of the protein $(49 \mathrm{kDa})$ encoded by the TgMIC1 gene and HIS-tag from the vector. Additionally, the $\mathrm{rTgMIC} 1$ protein was purified by $\mathrm{Ni}^{2+}$-affinity chromatography (Fig. 3d). Thus, these results suggest that rTgMIC1 was successfully expressed and purified.

\section{Generation and specific identification of TgMIC1 polyclonal antibody}

For further research, the purified rTgMIC1 protein was injected into the New Zealand white rabbit by multiple back injections, and antiserum was collected after the fourth booster immunization. The polyclonal antibody $(\mathrm{pAb})$ against TgMIC1 was purified by Protein $\mathrm{A}$; the titer was approximately $1: 12,800$, as estimated by ELISA assay (Fig. 4a), with purity $>90 \%$, as indicated by SDSPAGE analysis (Fig. 4b). The specificity of rTgMIC1 and pET30a-MIC1 was identified by the polyclonal antibodies against TgMIC1 as a clear band of approximately $60 \mathrm{kDa}$, whereas the other recombinant parasite proteins, pET30a-MIC4, pET30a-MIC6 and pET28a-ROP18, were not identified by the TgMIC1 antibodies (Fig. 4c). Moreover, parasite proteins of different types of T. gondii strains, such as $\mathrm{RH}, \mathrm{TgCtwh} 3$ and TgCtwh6 total proteins, were identified by TgMIC1 antibodies; other parasite proteins, such as Plasmodium and Schistosoma total protein, were not detected by TgMIC1 antibodies (Fig. 4d). Immunofluorescence with TgMIC1 (red) was performed to determine the localization of TgMIC1 in GFP-RH-infected HFF cells (Fig. 4e). These results indicated that the obtained TgMIC1 antibodies which located in the apex

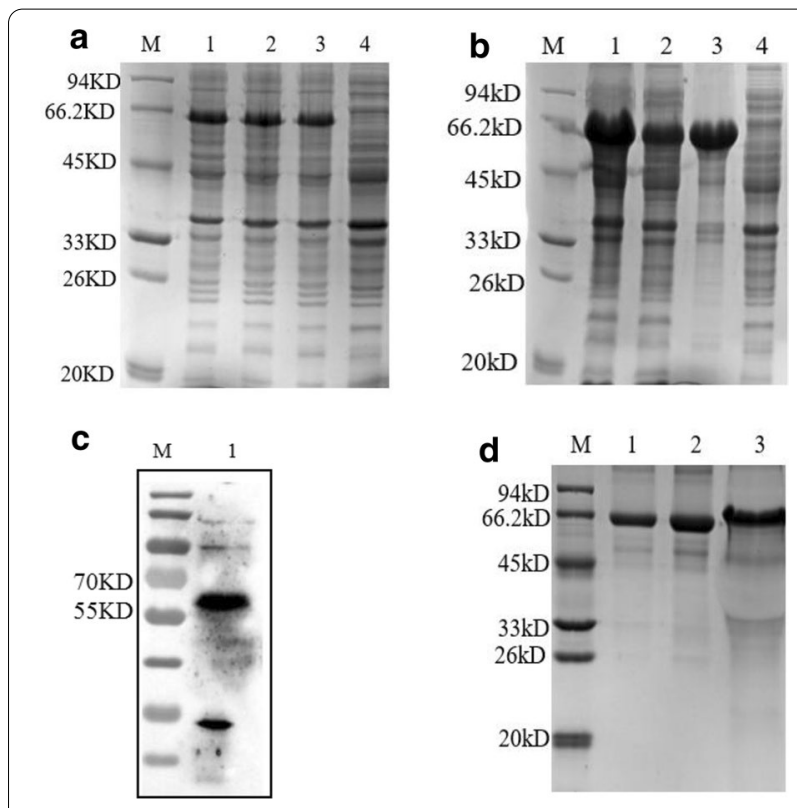

Fig. 3 SDS-PAGE and western blot analysis of the rTgMIC1 protein. a Expression of pET30a-MIC1/BL21 in small amounts. Lane M: protein marker; lane 1-3: mono-clone picked from conversion plates after induction with IPTG; lane 4: uninduced control. b Large amounts of expression detection. Lane M: protein marker; lane 1: proteins in pET30a-MIC1/BL21 after induction with IPTG; lane 2: supernatant of PET30a-MIC1/BL21 bacteria after ultrasonication; lane 3: precipitation of pET30a-MIC1/BL21 bacteria after ultrasonication; lane 4: uninduced control. c Western blot analysis of the rTgMIC1. Lane M: protein marker; lane 1: rTgMIC1 detected by HIS monoclonal antibodies. d The rTgMIC1 purified by $\mathrm{Ni}^{2+}$-affinity chromatography. Lane $\mathrm{M}$ : protein marker; lane 1: $0.5 \mathrm{mg} / \mathrm{ml} \mathrm{BSA}$; lane 2: $1.0 \mathrm{mg} / \mathrm{ml} \mathrm{BSA}$; lane 3: purified rTgMIC1 proteins

of parasite with high specificity can be used for further experiments.

\section{Differential protein expression of TgMIC1 in TgCtwh3 and TgCtwh6 strains}

Western blot analysis revealed that the relative protein expression of TgMIC1 ( $t$-test: $t(4)=4.577, p=0.0102)$ in TgCtwh3 tachyzoites was twofold higher compared to TgCtwh6 tachyzoites (Fig. 5), in agreement with the differential mRNA expression of TgMIC1. Inspired by these results, we hypothesize that differentially expressed TgMIC1 is likely one of virulence regulators between TgCtwh3 and TgCtwh6 strains.

\section{Evaluation the role of TgMIC1 for parasite invasion and replication}

From the superimposed picture, red parasites are the parasites that invade the cell, yellow ones are the parasites outside the cell, and the nucleus is blue. The results showed that the invasion efficiency of TgCtwh3, TgCtwh 6 and TgCtwh 3 plus anti-mic1 was $67 \%, 40 \%$ and 

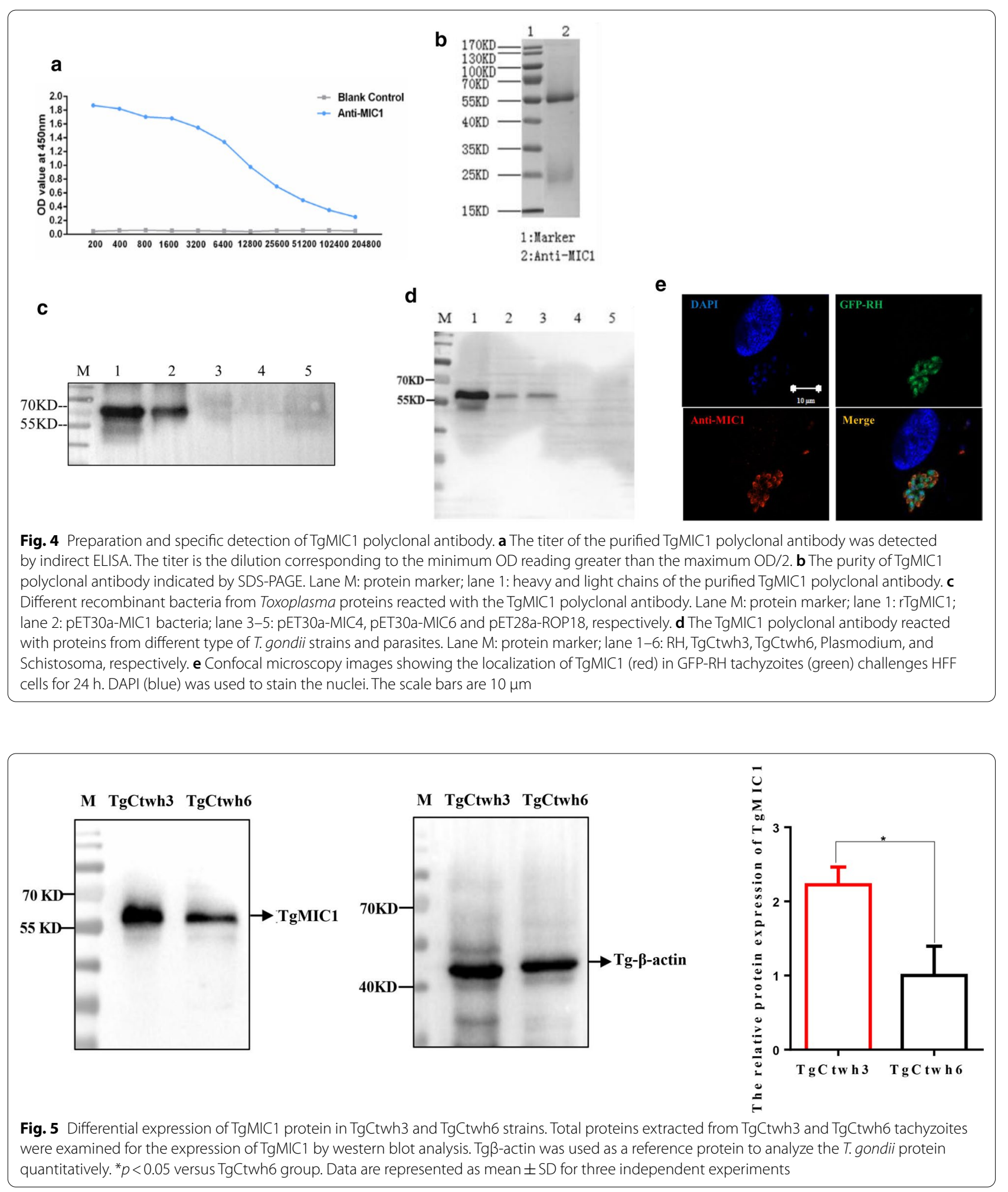

$43 \%$, respectively (Fig. 6a-b). The invasion efficiency of TgCtwh3 was higher than that of TgCtwh6 (ANOVA: $F$ $(3,16)=61.13, p<0.001)$, and the invasion efficiency of
TgCtwh 3 was reduced by TgMIC1 polyclonal antibody to some extent (ANOVA: $F(3,16)=61.13, p=0.0170$ ). Furthermore, the intracellular replication capability of 


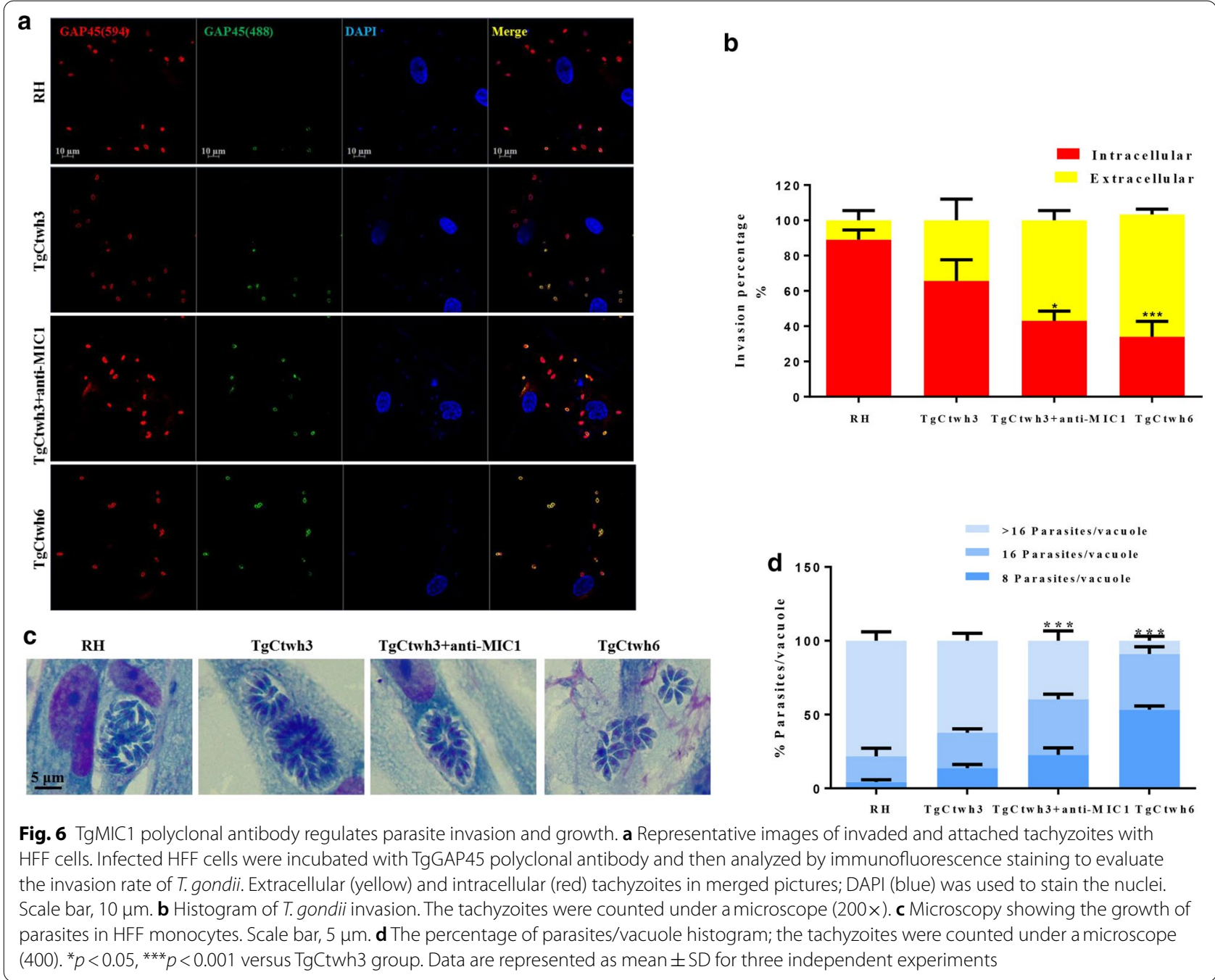

TgCtwh 3 was also attenuated by the TgMIC1 polyclonal antibody compared with the untreated group (ANOVA: $F(6,24)=115.6, p<0.001)$ (Fig. $6 \mathrm{c}-\mathrm{d})$. These results indicate that the level of TgMIC1 affects TgCtwh3 attachment and replication capability in HFF cells.

\section{Discussion}

Much progress has been made toward understanding $T$. gondii's strain-specific virulence factors and their effects on the host immune response. However, most attention has been focused on the dominant strains in North America and Europe; the information is less clear when considering the dominant strains in other regions, especially in China [20-22]. ROP18/ROP5/ROP17 specifically counteracts murine defense mechanisms by phosphorylating and inactivating immunity-related GTPases (IRGs). Moreover, ROP18 can phosphorylate host activating transcription factor $6 \beta$ (ATF6 $\beta$ ), leading to the proteasomal degradation of ATF6 $\beta$ and thereby interrupting its role in antigen presentation by DCs [23, 24]. Generally, the aforementioned parasite-derived polymorphic effectors represent most of the differences in acute virulence among these three classical lineages. However, this does not seem to explain the differences in toxicity between TgCtwh 3 and TgCtwh 6 strains; neither genetic variation in exon regions nor differential expression of ROP5 and ROP18 was noted between these two strains (unpublished data). Given its role in altering host gene transcription, ROP16 has been extensively studied as an important virulence-related molecule. Moreover, TgCtwh 3 and TgCtwh 6 of type Chinese I carry ROP16 and GRA1 $5_{\text {II }}$ effectors [25], and there is no significant difference in the virulence of TgCtwh $3 \Delta$ rop 16 and TgCtwh3 WT strains in mice [26]. The genotype varies among different strains of T. gondii and results in divergent resistance to host defense mechanisms, suggesting that type I Chinese strains have unique virulence characteristics and pathogenesis. 
Recent advances in the field of $T$. gondii research have revealed that microneme secretion is regulated by phosphatidic acid, cyclic guanosine monophosphate and calcium [27, 28]. These TgMIC proteins cooperate with actomyosin system control tachyzoite invasion and egress from infected cells [13, 29]. Among the released proteins, TgMIC1, TgMIC4 and TgMIC6 form a complex. This resultant complex, together with other T. gondii proteins, acts on the adhesion and invasion of host cells and promotes the virulence of T. gondii $[13,30]$. Our results demonstrated that the mRNA level of TgMIC1 in TgCtwh3 is apparently higher than in TgCtwh6. Given the remarkable role of TgMIC1, we developed rTgMIC1 protein and pAbs against it to identify its protein expression in these two strains. Furthermore, the native gene of TgMIC1 has several features which may lead to poor expression; hence, we strategically optimized the underlying DNA sequence of TgMIC1 to improve its mRNA stability and recombinant protein expression in E. coli. Compared with that of the actual codon frequency, the squared difference of the preferred codon frequency changed from 1.85 to 3.17 . The GC content throughout the sequence was homogenized to increase the half-life of the mRNA. Moreover, the mRNA secondary structure has been reduced, which improved the translation efficiency. These modifications helped us to obtain the high yield and high concentration of TgMIC1 protein. In our study, the produced pAbs could recognize not only the recombinant TgMIC1 but also the natural TgMIC1 protein in T. gondii but not those in Plasmodium and Schistosoma.

Factors such as invasiveness, intracellular replication capability and the strength and characteristics of the induced immune response in host cells combine to determine T. gondii's virulence. A previous study reported that the invasion by TgMIC1ko parasites was reduced by half compared to wild type [31]. An important observation in the present study is that the protein level of TgMIC1 in TgCtwh3 was significantly higher than that in TgCtwh6, which may cause the difference invasiveness or replication capability of $T$. gondii to host cells. Consistent with our hypothesis, the two-color and experimental analysis of $T$. gondii-infected HFF cells revealed that elimination of TgMIC1 protein by adding exogenous polyclonal antibodies hinders the invasiveness and intracellular replication capability of TgCtwh3. Invasion of host cells by $T$. gondii involves carbohydrate recognition [32, 33], and TgMIC1 has lectin domains that recognize oligosaccharides with sialic acid in the terminal position [34]. rTgMIC1 stimulates dendritic cells and macrophages produce proinflammatory cytokines via engaging TLR2 and TLR4 [17]. TgMIC1 was highly expressed in the Chinese 1 genotype $T$. gondii high virulent strain TgCtwh3, which enhanced its invasion ability and, in contrast, may contribute to T. gondii proliferation through participation in cellular immunity. Further experiments with TgCtwh3MIC1 ko and TgCtwh3-MIC1 ko+MIC1 strains constructed using CRISPR/CAS9 technology are needed to study the TgMIC1 function in TgCtwh3 and TgCtwh6 strains.

\section{Conclusions}

Taken together, we have successfully developed rTgMIC1 and its pAb. These outcomes can be applied to many experiments, from western blotting and immunofluorescence to in vivo function analysis. Furthermore, our work clearly shows the effect of differences in TgMIC1 levels on Chinese I Toxoplasma intracellular invasion and proliferation; this represents an important step toward our understanding of how TgCtwh3 and TgCtwh6 vary in their virulence in mice.

\section{Acknowledgements}

Not applicable.

\section{Authors' contributions}

LY conceived and designed the study and critically revised the manuscript. YW, CH and RZ carried out the experiments and drafted the manuscript. JZ, $F Z$, JL, QL, JD, DC, YC and JS contributed to the revision of the manuscript. All authors read and approved the final manuscript.

\section{Funding}

This work was supported in part by the National Key R\&D Program of China (2017YFD0500400 to LY), National Natural Science Foundation of China (82072304, 81871671 and 81572022 to LY, 81802003 to YY C), Outstanding Young Scholars Financial Support of Anhui Medical University (0113014104 to $L Y$ ) and promotion plan of basic and clinical cooperative research in Anhui Medical University (2019xkjT023 to LY).

\section{Availability of data and materials}

The datasets used and/or analyzed during the current study are available from the corresponding author on reasonable request.

\section{Declaration}

Ethics approval and consent to participate

All animal experiments were conducted in strict accordance with the Chinese National Institute of Health Guide for the Care and Use of Laboratory Animals and approved by the Institutional Review Board of Anhui Medical University Institute of Biomedicine (Permit Number: AMU26-081108).

\section{Consent for publication}

Not applicable.

\section{Competing interests}

The authors declare that they have no competing interests.

\section{Author details}

${ }^{1}$ Department of Microbiology and Parasitology, Anhui Provincial Laboratory of Microbiology and Parasitology; Anhui Key Laboratory of Zoonoses, School of Basic Medical Sciences, Anhui Medical University, 81 Meishan Road, Hefei 230032, Anhui Province, People's Republic of China. ${ }^{2}$ The Clinical Laboratory of the Third People's Hospital of Heifei, Hefei, China. ${ }^{3}$ Department of Biochemistry and Molecular Biology, Anhui Medical University, Hefei, China. ${ }^{4}$ Department of Health Inspection and Quarantine, School of Public Health, Anhui Medical University, Hefei, China. 
Received: 24 January 2021 Accepted: 28 April 2021

Published online: 13 May 2021

\section{References}

1. Dubey JP, Lago EG, Gennari SM, Su C, Jones JL. Toxoplasmosis in humans and animals in Brazil: high prevalence, high burden of disease, and epidemiology. Parasitology. 2012;139:1375-424.

2. Sullivan AM, Zhao X, Suzuki Y, Ochiai E, Crutcher S, Gilchrist MA. Evidence for finely-regulated asynchronous growth of Toxoplasma gondii cysts based on data-driven model selection. PLoS Comput Biol. 2013:9:e1003283

3. Kasper LH, Buzoni-Gatel D. Some Opportunistic Parasitic Infections in AIDS: Candidiasis, Pneumocystosis, Cryptosporidiosis Toxoplasmosis. Parasitol Today. 1998;14:150-6.

4. Howe DK, Sibley LD. Toxoplasma gondii comprises three clonal lineages: correlation of parasite genotype with human disease. J Infect Dis. 1995; 172:1561-6.

5. Saeij JP, Boyle JP, Boothroyd JC. Differences among the three major strains of Toxoplasma gondii and their specific interactions with the infected host. Trends Parasitol. 2005:21:476-81.

6. Wang L, Chen H, Liu D, Huo X, Gao J, Song X, et al. Genotypes and mouse virulence of Toxoplasma gondii isolates from animals and humans in China. PLoS ONE. 2013;8:e53483.

7. Li M, Mo XW, Wang L, Chen H, Luo QL, Wen HQ, et al. Phylogeny and virulence divergency analyses of Toxoplasma gondii isolates from China. Parasit Vectors. 2014;7:133.

8. Wang L, Cheng HW, Huang KQ, Xu YH, Li YN, Du J, et al. Toxoplasma gondi prevalence in food animals and rodents in different regions of China: isolation, genotyping and mouse pathogenicity. Parasit Vectors. 2013;6:273.

9. Carruthers VB, Sibley LD. Sequential protein secretion from three distinct organelles of Toxoplasma gondii accompanies invasion of human fibroblasts. Eur J Cell Biol. 1997;73:114-23.

10. Hakansson S, Charron AJ, Sibley LD. Toxoplasma evacuoles: a two-step process of secretion and fusion forms the parasitophorous vacuole. EMBO J. 2001;20:3132-44.

11. Carruthers VB, Giddings OK, Sibley LD. Secretion of micronemal proteins is associated with toxoplasma invasion of host cells. Cell Microbiol. 1999;1:225-35

12. Lovett JL, Sibley LD. Intracellular calcium stores in Toxoplasma gondii govern invasion of host cells. J Cell Sci. 2003;116:3009-16.

13. Reiss M, Viebig N, Brecht S, Fourmaux MN, Soete M, Di Cristina M, et al. Identification and characterization of an escorter for two secretory adhesins in Toxoplasma gondii. J Cell Biol. 2001;152:563-78.

14. Saouros S, Edwards-Jones B, Reiss M, Sawmynaden K, Cota E, Simpson P, et al. A novel galectin-like domain from Toxoplasma gondii micronemal protein 1 assists the folding, assembly, and transport of a cell adhesion complex. J Biol Chem. 2005;280:38583-91.

15. Cerede O, Dubremetz JF, Soete M, Deslee D, Vial H, Bout D, et al. Synergistic role of micronemal proteins in Toxoplasma gondii virulence. J Exp Med. 2005;201:453-63.

16. Lourenco EV, Bernardes ES, Silva NM, Mineo JR, Panunto-Castelo A, Roque-Barreira MC. Immunization with MIC1 and MIC4 induces protective immunity against Toxoplasma gondii. Microbes Infect. 2006;8:1244-51.

17. Sardinha-Silva A, Mendonca-Natividade FC, Pinzan CF, Lopes CD, Costa $\mathrm{DL}$, Jacot D, et al. The lectin-specific activity of Toxoplasma gondii microneme proteins 1 and 4 binds Toll-like receptor 2 and $4 \mathrm{~N}$-glycans to regulate innate immune priming. PLoS Pathog. 2019;15:e1007871.
18. Hober S, Nord K, Linhult M. Protein A chromatography for antibody purification. J Chromatogr B Analyt Technol Biomed Life Sci. 2007;848:40-7.

19. Jia Y, Marq JB, Bisio H, Jacot D, Mueller C, Yu L, et al. Crosstalk between PKA and PKG controls pH-dependent host cell egress of Toxoplasma gondii. EMBO J. 2017;36:3250-67.

20. Chen ZW, Gao JM, Huo XX, Wang L, Yu L, Halm-Lai F, et al. Genotyping of Toxoplasma gondii isolates from cats in different geographic regions of China. Vet Parasitol. 2011;183:166-70.

21. Rosowski EE, Lu D, Julien L, Rodda L, Gaiser RA, Jensen KD, et al. Strainspecific activation of the NF-kappaB pathway by GRA15, a novel Toxoplasma gondii dense granule protein. J Exp Med. 2011;208:195-212.

22. Yamamoto M, Standley DM, Takashima S, Saiga H, Okuyama M, Kayama $\mathrm{H}$, et al. A single polymorphic amino acid on Toxoplasma gondii kinase ROP16 determines the direct and strain-specific activation of Stat3. J Exp Med. 2009;206:2747-60.

23. Hunter CA, Sibley LD. Modulation of innate immunity by Toxoplasma gondii virulence effectors. Nat Rev Microbiol. 2012;10:766-78.

24. Behnke MS, Fentress SJ, Mashayekhi M, Li LX, Taylor GA, Sibley LD. The polymorphic pseudokinase ROP5 controls virulence in Toxoplasma gondii by regulating the active kinase ROP18. PLoS Pathog. 2012;8:e1002992.

25. Cheng W, Liu F, Li M, Hu X, Chen H, Pappoe F, et al. Variation detection based on next-generation sequencing of type Chinese 1 strains of Toxoplasma gondii with different virulence from China. BMC Genomics. 2015;16:888.

26. Wang C, Cheng W, Yu Q, Xing T, Chen S, Liu L, et al. Toxoplasma Chinese 1 Strain of WH3Deltarop 16l/III /gra15II genetic background contributes to abnormal pregnant outcomes in murine model. Front Immunol. 2018;9:1222.

27. Carruthers VB, Sibley LD. Mobilization of intracellular calcium stimulates microneme discharge in Toxoplasma gondii. Mol Microbiol. 1999:31:421-8.

28. Tomley FM, Soldati DS. Mix and match modules: structure and function of microneme proteins in apicomplexan parasites. Trends Parasitol. 2001;17:81-8.

29. Pavlou G, Biesaga M, Touquet B, Lagal V, Balland M, Dufour A, et al. Toxoplasma Parasite twisting motion mechanically induces host cell membrane fission to complete invasion within a protective vacuole. Cell Host Microbe. 2018;24(81-96):e5.

30. Friedrich N, Santos JM, Liu Y, Palma AS, Leon E, Saouros S, et al. Members of a novel protein family containing microneme adhesive repeat domains act as sialic acid-binding lectins during host cell invasion by apicomplexan parasites. J Biol Chem. 2010;285:2064-76.

31. Sawmynaden K, Saouros S, Friedrich N, Marchant J, Simpson P, Bleijlevens $B$, et al. Structural insights into microneme protein assembly reveal a new mode of EGF domain recognition. EMBO Rep. 2008;9:1149-55.

32. Carruthers VB, Hakansson S, Giddings OK, Sibley LD. Toxoplasma gondii uses sulfated proteoglycans for substrate and host cell attachment. Infect Immun. 2000;68:4005-11.

33. Paing MM, Tolia NH. Multimeric assembly of host-pathogen adhesion complexes involved in apicomplexan invasion. PLoS Pathog. 2014; 10:e1004120.

34. Lourenco EV, Pereira SR, Faca VM, Coelho-Castelo AA, Mineo JR, RoqueBarreira MC, et al. Toxoplasma gondii micronemal protein MIC1 is a lactose-binding lectin. Glycobiology. 2001;11:541-7.

\section{Publisher's Note}

Springer Nature remains neutral with regard to jurisdictional claims in published maps and institutional affiliations. 